\title{
HEALTH HAZARDS WITH ADULTERATED SPICES: SAVE THE “ONION TEARS”
}

\author{
ABDUL KADER MOHIUDDIN*
}

Secretary and Treasurer, Dr. M. Nasirullah Memorial Trust, Tejgaon, Dhaka, Bangladesh. Email: trymohi@gmail.com

Received: 17 March 2020, Revised and Accepted: 21 April 2020

\begin{abstract}
Spices are among the top five most commonly adulterated food types because they are expensive commodities that are processed before sale, used most frequently and consumed by mass population. There is a strong incentive to pollute. In Bangladesh, different types of grounded spices powders are available such as onion, ginger, coriander, chili, turmeric, and cumin. These powdered spices are commercially processed and packaged by some leading food industries, while some local non-branded industries also exist. Nowadays, people are busy with their carriers, the demand of branded spices powder is increasing gradually. In general, most of the people tend to buy loose spices from the local grocery store if branded and packaged spices are not available. This increases the risk of consuming adulterated spices. Unlike this particular adulterant is not unhealthy (but illegal), most of the adulterants are unhealthy and can cause serious and fatal damage to our system if consumed regularly. The escalating market of this product implies that in Bangladesh, this tradition is increasingly attaining momentum. Spices are consumed in various forms such as whole spices, ground spices, oleoresins, and extracts. Spices play an important role in enhancing the flavor and taste of processed foods. They are also used in medicine because of their carminative stimulating and digestive properties. Ground spices may be adulterated with artificial colors, starch, chalk powder, etc. to increase their weight and enhance appearance. High value ground spices are frequently adulterated for economic gains. Adulteration is difficult to identify by visual and sensory inputs alone. Although there are few renowned food industries, peoples are always suspicious about these products. However, there are still not enough investigations for the quality check of all these branded powdered products.
\end{abstract}

Keywords: Food adulteration, Food safety laws and regulations, Public perception of adulteration, Adulteration practices, Possible health outcomes of adulteration.

(C) 2020 The Authors. Published by Innovare Academic Sciences Pvt Ltd. This is an open access article under the CC BY license (http://creativecommons org/licenses/by/4. 0/) DOI: http://dx.doi.org/10.22159/ijms.2020.v8i3.36439

\section{BACKGROUND}

Prices of onion started soaring after India banned its export on September 29, 2019. The following day, onion cost doubled in Bangladesh [1]. The price hike heated up the onion market in Bangladesh as the country meets a portion of its annual demand through import because of inadequate domestic production. Within the span of 2 months, the price raised more than $500 \%$ which is the highest in the history of Bangladesh [2]. Bangladesh produces 1.7 million-1.9 million tons of onion annually and imports 700,000 tons-1.1 million tons to meet the domestic demand [3-6]. The government has now decided to start flying in onions from Turkey and Egypt and continued the process until new produces from the Bangladesh farmers and shipment of consignments through the sea arrive $[7,8]$. The Financial Times reported that the Indian government itself pledged to import onion after prices increased $500 \%$ from the start of the year [9]. If "onion prices falling tears," we have to save tears for other adulterated spices. The problem is not only ignoring the human rights for safer food but also endangering public health seriously with numerous acute and chronic diseases.

\section{INTRODUCTION}

Among a database of more than 1000 records of food adulteration worldwide between 1980 and 2010, more than $10 \%$ of scholarly articles and nearly $90 \%$ of media reports related to spices, many featuring toxic synthetic chemical dyes of similar chemical structure [10]. Looking at the past 10 years of data for herbs/spices, chili powder, turmeric, and saffron have the highest number of fraud records and chili powder, turmeric, and paprika (spices to be powdered for cooking) have the highest number of distinct adulterants associated with them [11]. Adulterated spices are not very different in appearance as compared to a batch of unadulterated spices. This makes it difficult for consumers to make an informed decision when purchasing the spices. Large food manufacturers use sophisticated technology that can compare the smells and tastes of various samples to detect possible adulteration. When buying spices loose, however, the possibility of adulteration is much higher. According to the WHO, food contamination and adulteration situation of Bangladesh are a serious public health concern. Unsafe/ contaminated food causes many acute and life-long diseases ranging from diarrheal diseases to various forms of cancer [12].

\section{Adulteration of spices: Public perception}

A recent study on consumer perception toward quality of spices powder available in Bangladesh shows that more than $90 \%$ of people believed that the spice powders are not of good quality. People also think that these adulterated spices powder may also responsible for different types of diseases including cancer, chronic nephritis, high blood pressure, headache, intestinal problem, and allergy [13]. The addition of wheat flour to powdered ginger with enough capsicum to restore the pungency and enough curcuma to maintain the natural color is a typical example of intentional adulteration [14]. Cinnamon is at very high risk of fraudulent adulteration, substitution, and dilution due to high price. Cassia, a low-grade cinnamon like bark which is toxic also, imported from China is cunningly added and mixed to cinnamon bulk. Cassia barks are tougher and thicker. They rarely give out any aromatic smell [15]. Argemone seeds are the common adulterant for mustard seeds. Green cardamom pods are often adulterated with "used" cardamom pods, or ones from which volatile oils have already been extracted [16]. Sawdust is the common adulterant used in cumin. Candied corn silk and colored plastic often make their way into dainty boxes of saffron [17]. This is also known as sophistication, which means that no stone is left untouched to produce a food item which would probably look even better than a naturally grown/produced food and food products.

\section{Ongoing adulteration practices}

The motivation for deliberate adulteration has usually been economic gain and involves common practices such as substituting plant material 


\section{Exhibit 1: Food Safety Laws and Regulations and Food Standards} in Bangladesh

Agricultural Products Market Act, 1950 (revised in 1985)

Fish Protection and Conservation Act, 1950 (latest amendment in 1995)

The Food Grain Supply (Prevention of Prejudicial Activity) Ordinance, 1956

The Bangladesh Pure Food Ordinance, 1959 (Bangladesh Ordinance No. LXVIII of 1959)

Agricultural Pest Ordinance, 1962

Agricultural Produce Markets Regulation Act, 1964 (revised in 1985)

The Cantonments Pure Food Act, 1966

Destructive Insects and Pests Rules, 1966 (Plant Quarantine) amended up to 1989

The Bangladesh Pure Food Rules, 1967

The Special Powers Act, 1974

The Animals Slaughter (Restriction) and Meat Control (Amendment) Ordinance, 1983

Marine Fisheries Ordinance, 1983 and Marine Fisheries Rules, 1983

Fish and Fish Products (Inspection and Quality Control) Ordinance, 1983

The Pesticide Ordinance, 1971 and The Pesticide Rules, 1985

Bangladesh Standards and Testing Institution Ordinance, 1985 (XXXVII of 1985)

The Radiation Protection Act, 1987

The Iodine Deficiency Disorder Prevention Act, 1989

The Essential Commodity Act, 1990

National Food Policy, 1996

National Agriculture Policy, 1996

Fish and Fish Products (Inspection and Quality Control) Rules, 1997

National Food and Nutrition Policy, 1997

National Fisheries Policy, 1998

National Policy for Safe Water and Sanitation, 1998

National Health Policy, 2000

Bangladesh Standards and Testing Institution (Amendment) Act, 2003

The Bangladesh Pure Food (Amendment) Act, 2005

Product Labeling Policy, 2006

National Livestock Policy, 2007

Fish Feed and Animal Feed Act, 2010

Export and Import Policy, 2009-2012

The Bangladesh Food Safety Act, 2013

BSTI Ordinance and many others

\section{Exhibit 2: Laboratories for Food Analysis}

Public Health Laboratory (IPH)

BSTI (Ministry of Industries)

Food Testing Laboratory (Ministry of Food \& Disaster management)

Food Testing Laboratory (Dhaka City Corporation)

Institute of Food Radiation Biology, Bangladesh Atomic Energy

Commission

Institute of Food Science Technology, BCSIR

Institute of Nutrition and Food Science, University of Dhaka

\section{Exhibit 3: WHO published - chemical exposure to toxic level}

\section{Carcinoma}

Cardiovascular disease

Kidney, liver dysfunction hormonal imbalance

Premature birth

Suppression of immune system

Impaired development of nervous system

Mental health problems and

Learning disabilities/cognitive dysfunction

from a totally different plant, for example, substituting black pepper fruits (Piper nigrum) with papaya seeds (Carica papaya) based on the similarity of the external appearance of black pepper and papaya. Another scenario consists of the addition of an inferior species containing less of the desirable active principal(s), or possessing less potent flavoring properties, but is commercially cheaper. Some additional common, ongoing adulteration practices for spices and herbs are as follows:

(a) Substitution (partial or complete) with solvent-exhausted material (e.g., exploiting exhausted ginger).

(b) Substituting the genuine plant part by other parts of the same plant which might be devoid of or possess less of the bioactive ingredients (e.g., the inclusion of clove stalks that contain less essential oil than the flower buds, stems in sage and laurel leaves, and black pepper in white pepper).

(c) Adulteration with common universal adulterants (bulking agents or fillers) such as ground grass, sawdust, straw, different kinds of cereals, starches, or bran (e.g., garlic powder and onion powder with corn starch, colored sawdust in turmeric, and red brick powder and bran in chili peppers).

(d) Inclusion of pure chemicals to spices that are pre-diluted with fillers such as starch and straw to artificially impart strong flavors and perception (e.g., piperine to black pepper, capsaicin to ginger, and curcumin to chili pepper)

(e) Addition of unrelated specific vegetable fillers to mimic morphological and micromorphological properties (e.g., olive leaves to oregano and sage).

(f) Inclusion of inorganic substances such as chalk, lime, powder of red brick, and metal salts (e.g., chili pepper powder with red brick and lead salts and turmeric with red lead chromate).

(g) Addition of non-permitted dyes (e.g., oil-soluble carcinogenic Sudan I-IV, metanil yellow, and dimethyl yellow and water-soluble dyes such as rhodamine B, a pink basic dye) [18]

\section{US import alert from Bangladesh and India}

According to the American Spice Trade Association (ASTA) and Indian Institute of Spice Research (IISR), different adulterants are used in spices to make them cheaper than original one likely color, starch of maize, wheat, tapioca and rice in turmeric, chilly and curry powder; brick powder grit, sand, dirt, and filth in chili powder; dung powder and common salt in coriander powder. Besides, these different foreign seed powder, color, floral waste, leaves, husks, and Sudan red may also have uses to make spices powder adulterated. Hence, consumer perception may be true in case of addition of suspected adulterants [19]. Journal of Sustainable Development Research, 2019, revealed intentional addition of brick dusts and artificial colors (in mixed spices, turmeric, cumin, and chili powders); dust from outer layer of rice (in mixed spices and coriander powder) and papaya seeds in pepper. Brick dust and sawdust cause respiratory problems. Coal tar and industrial dyes in powdered spices are carcinogenic (causes cancer upon long-term exposure), especially metanil yellow aniline dyes in turmeric powder [20]. In September 2013, the US FDA announced voluntary recall by distributors of "PRAN" brand turmeric powder, a Bangladeshi company, due to elevated levels of lead [21]. Additional studies identified the presence of contaminated spices originating from India and Bangladesh in markets in Boston, MA [22-24]. The FDA has released detailed import alerts for lead-adulterated turmeric, naming importing companies and the country of origin. All are from Bangladesh and India [25].

\section{The "Turmeric Turmoil"}

A relative of the ginger root, turmeric is grown predominantly in India, as well as Bangladesh, Myanmar, China, and Nigeria. Uptake of lead from soil into the turmeric is a possible, but unlikely, source of contamination, as the previous researchers estimate the maximum uptake of lead into the root of the plant to be approximately $10 \%[26]$. Very recently, researchers of Stanford University, California, and ICDDR, B exposed the nefarious act of yellow pigment (lead chromate) adulteration to enhance brightness in 7 out of the 9 major turmeric producing districts [27]. Turmeric lead and chromium concentrations were highest in Dhaka and Munshiganj districts. Analyzing soil samples and gathering interviews with farmers and spice makers, researchers have found lead levels in turmeric that exceed national limits by up to 500-fold [28-30]. "Unlike other metals, there is no safe consumption 
Table 1: Toxic elements in noxious addition of spices with possible outcomes [20], [32-43]

\begin{tabular}{|c|c|c|}
\hline Contaminants & Spice type & Possible outcome \\
\hline $\begin{array}{l}\text { Coloring agents chrome, tartrazine, } \\
\text { and erythrosine }\end{array}$ & Mixed spices $=$ & Cancer in kidney, liver, skin, prostate, and lungs \\
\hline Coal tar and industrial dyes & Powdered spices & Carcinogenic \\
\hline Brick dust & Chili powder & Respiratory problem \\
\hline Metanil yellow aniline dyes & Turmeric powder & Carcinogenic \\
\hline Yellow and Sudan red colors (ibid) & Chili powder & Tumors in liver and bladder and finally for cancer \\
\hline Lead(II) chromate (PbCrO4) & Turmeric powder & $\begin{array}{l}\text { Lead poisoning may cause neurotoxicity, nephrotoxicity, anemia, reduced male } \\
\text { fertility. Chromium (VI) is involved in the process of carcinogenesis. }\end{array}$ \\
\hline $\begin{array}{l}\text { Sudan red (typically used to color } \\
\text { oils and waxes, including shoe } \\
\text { polish) }\end{array}$ & Paprika, chili powders & $\begin{array}{l}\text { Class III carcinogens, considered harmful to human health due to their } \\
\text { teratogenicity, genotoxicity, and carcinogenicity. }\end{array}$ \\
\hline Cinnamon & Cassia & Cassia cinnamon, but not Ceylon, is a very rich source of coumarin. \\
\hline Mustard seeds. & Argemone seeds & $\begin{array}{l}\text { Argemone oil poisoning included vomiting, diarrhea, nausea, swelling of } \\
\text { limbs, erythema, pitting edema, and breathlessness }\end{array}$ \\
\hline Green cardamom pods & Used pods & $\begin{array}{l}\text { Newer pods will be plum and full, but used ones will be wrinkled and feel } \\
\text { empty, devoid of any health benefits. }\end{array}$ \\
\hline Black pepper & $\begin{array}{l}\text { Papaya seeds, piperine, } \\
\text { expired green and red chili }\end{array}$ & $\begin{array}{l}\text { Papain content may cause natural uterine contraction and may lead to } \\
\text { abortions. }\end{array}$ \\
\hline
\end{tabular}

limit for lead, it's a neurotoxin in its totality," said the papers' senior author Stephen Luby, professor of medicine and the director of research for Stanford's Center for Innovation in Global Health. "We cannot console ourselves proposing that if the contamination was down to such and such level, it would have been safe" [31].

\section{Health hazards of consuming contaminated spices}

Adulteration is attributed primarily to increased demand or supply shortage of the spices and aromatic herbs. As spice trading has exponentially increased globally, herbs and spices have become prone to adulteration, which can be deliberate or unintentional. Deliberate adulteration is usually economically motivated, aimed at maximizing profit margins, whereas unintentional adulteration is often attributed to improper harvesting or processing of the plant material or collecting/ substituting closely related species $[32,33]$. Spices and herbs, being highpriced commodities, have been often subjected to adulteration in many ways which reduce their quality and potentially have harmful health implications. The motivation for spice fraud is largely attributed to economical interest to gain greater profit margins and such adulteration of spices can have serious implications for public health.

\section{CONCLUSION AND RECOMMENDATION}

Worse still, in many cases, the used and exhausted spices are mixed with fresh ones in small quantities to confuse the consumer. The most obvious and simplest reason is to increase profit. A manufacturer may use a cheap filler that is easily disguised in the spice to increase the volume sold, thereby cutting the cost of pure spice and thereby increasing the ultimate profit margin. The relevant policy-makers do need to look into the issue seriously, if they are really interested to prevent health hazards from contamination and adulteration. A robust surveillance is necessary for assessing marketed food items in Bangladesh, prompt notification of public health emergency, and a year-round campaign against notorious daredevils.

\section{REFERENCES}

1. UNB, Chattogram. Where did the Rotten Onion Come from? The Price of Onion Crossed Tk 250 per kg in Dhaka's Markets. The Daily Star; 2019.
2. TBS Report. Onion Price $2^{\text {nd }}$ Highest in Bangladesh after Maldives: Afghanistan, the Only Exporter in the Region, has the Lowest Prices. The Business Standard; 2019.

3. Pakbir MM. Unrealistic Price Hike of Commodity Products and Restoring Accountability. The Daily Observer; 2019.

4. Staff Correspondent. Fears of Further Onion Price Hike in Bangladesh as India Bans Export. http://www.bdnews24.com. [Last accessed on 2109 Sep 29].

5. The Financial Express. India Caps Minimum Export Price of Onion at $\$ 850$ Per Tonne. The Financial Express; 2019.

6. Akter F. Onion: Getting Out of Pungent Dependency. New Age; 2019.

7. Staff Correspondent. Onion Prices Skyrocketing. Johannesburg, Gauteng: Daily Sun; 2019.

8. Front Page. Govt Flying in Onion from Egypt, Turkey as Prices Continue to Soar. The Daily Observer; 2019.

9. AtiK F. Who's to Blame as Onion Prices Shoot through the Roof in Bangladesh? http://www.bdnews24.com. [Last accessed on 2019 Nov 16].

10. Moore JC, Spink J, Lipp M. Development and application of a database of food ingredient fraud and economically motivated adulteration from 1980 to 2010. J Food Sci 2012;77:R118-26.

11. Everstine K. Public food standards. Food Saf Technol 2019;27:39-42.

12. WHO Bangladesh. Food Safety. Available from: http://www.searo.who. int/bangladesh/areas/foodsafety/en.

13. Sattar S, Das PC, Hossain MS, Sarower K, Uddin MB. Study on consumer perception towards quality of spices powder available in Bangladesh. Open J Saf Sci Technol 2019;9:137-44.

14. Rahman MA, Sultan MZ, Rahman MS, Rashid MA. Food adulteration: A serious public health concern in Bangladesh. Bangladesh Pharm J 2015;18:1-7.

15. Gonzalez A. Adulterated Herbs and Spices: Steps You Can Take. Waltham, Massachusetts: Thermo Fisher Scientific; 2019.

16. Beniwal A, Khetarpaul N. Knowledge of consumers regarding the nature and extent of adulteration of Indian foods. Nutr Health 1999;13:153-60.

17. Morozzi P, Zappi A, Gottardi F, Locatelli M, Melucci D. A quick and efficient non-targeted screening test for saffron authentication: Application of chemometrics to gas-chromatographic data. Molecules 2019;24:2602.

18. Osman AG, Raman V, Haider S, Ali Z, Chittiboyina AG, Khan IA. Overview of analytical tools for the identification of adulterants in commonly traded herbs and spices. J AOAC Int 2019;102:376-85.

19. Detection and Quantification of Spice Adulteration By Near Infrared Hyperspectral Imaging. Thesis Presented to Department of Food Science, Faculty of Agric Sciences, Stellenbosch University. March 
2011. Available from: https://www.core.ac.uk/download/pdf/37326273. pdf. [Last accessed on 2019 Nov 20].

20. Mohiuddin AK. Chemical contaminants and pollutants in the measurable life of Dhaka city. Eur J Sustain Dev Res. 2019;3:57-73.

21. Cowell W, Ireland T, Vorhees D, Heiger-Bernays W. Ground turmeric as a source of lead exposure in the United States. Public Health Rep 2017; 132:289-93.

22. Lin CG, Schaider LA, Brabander DJ, Woolf AD. Pediatric lead exposure from imported Indian spices and cultural powders. Pediatrics 2010;125:e828-35

23. Woolf AD, Woolf NT. Childhood lead poisoning in 2 families associated with spices used in food preparation. Pediatrics 2005; 116:e314-8.

24. Bergkvist C, Kippler M, Hamadani JD, Grandér M, Tofail F, Berglund $\mathrm{M}$, et al. Assessment of early-life lead exposure in rural Bangladesh. Environ Res 2010;110:718-24.

25. Gleason K, Shine JP, Shobnam N, Rokoff LB, Suchanda HS, Hasan MO, et al. Contaminated turmeric is a potential source of lead exposure for children in rural Bangladesh. J Environ Public Health 2014;2014:730636.

26. Rahim SA, Idris WM, Rahman ZA, Lihan T, Omar R, Yan LK. Heavy metal content in selected flavouring plants and in ultra-basic soil of Felda Rokan Barat, Negeri Sembilan, Malaysia. Sains Malaysiana 2012;41:11-21.

27. Pashler A. Turmeric May Contain Dangerous Levels of Lead. Brighton, East Sussex: Medical News Today; 2019.

28. Forsyth JE, Nurunnahar S, Islam SS, Baker M, Yeasmin D, Islam MS et al. Turmeric means "yellow" in Bengali: Lead chromate pigments added to turmeric threaten public health across Bangladesh. Environ Res 2019;179:108722.

29. Cassella C. People are Adding Disturbing Levels of Lead to Turmeric, Study Shows. Science Alert; 2019

30. Nabil MZ. Lead Polished Turmeric Widespread, Blameable for Raised Blood-lead Level. ICDDR, B News Desk; 2019.

31. Jordan R. Stanford Researchers Find Lead in Turmeric. Palo Alto,
California: Stanford University Press; 2019

32. Jaiswal S, Yadav DS, Mishra MK, Gupta AK. Detection of adulterants in spices through chemical method and thin layer chromatography for forensic consideration. Int J Dev Res 2016;6:8824-7.

33. Shruti S, Shah H, Shah K. Identification and estimation of non-permitted food colours (metanil yellow and aniline dyes) in turmeric powder by rapid color test and thin layer chromatography. World J Pharm Pharm Sci 2017;6:2034-45.

34. Kader MA. Heavy metals: The notorious daredevils of daily personal care products. Am Res J Dermatol 2019;1:68-74.

35. DesMarais TL, Costa M. Mechanisms of chromium-induced toxicity. Curr Opin Toxicol 2019;14:1-7.

36. Alim UN, Butt YN, Zahra N. Sudan dyes and their potential health effects. Pak J Biochem Mol Biol 2016;49:29-35.

37. Kouame K, Peter AI, Akang EN, Adana M, Moodley R, Naidu EC, et al. Effect of long-term administration of Cinnamomum cassia silver nanoparticles on organs (kidneys and liver) of Sprague-Dawley rats. Turk J Biol 2018;42:498-505.

38. Lungarini S, Aureli F, Coni E. Coumarin and cinnamaldehyde in cinnamon marketed in Italy: A natural chemical hazard? Food Addit Contam Part A Chem Anal Control Expo Risk Assess 2008;25: 1297-305.

39. Das M, Khanna SK. Clinicoepidemiological, toxicological, and safety evaluation studies on argemone oil. Crit Rev Toxicol 1997;27:273-97.

40. Conscious Food. How to Check for Adulteration in Spices. Available from: https://www.consciousfood.com/check-adulteration-spices.

41. Kader MA. Dengue protection and cure: Bangladesh perspective. Eur J Sustain Dev Res 2019;4:15959-60.

42. Dissanayake DR, Herath D, Dissanayake MD, Chamikara M. The length polymorphism of the locus PsbA-TrnH is idyllic to detect the adulterations of black pepper with papaya seeds and chili. J Agric Sci 2016;11:74.

43. Curl CL, Fenwick GR. On the determination of papaya seed adulteration of black pepper. Food Chem 1983;12:241-7. 